\title{
PEMANFAATAN BUNGA PUKUL DELAPAN (Turnera subulata) SEBAGAI TANAMAN INANG BAGI PREDATOR DAN PARASITOID ULAT API (Studi Kasus PT. Tritunggal Sentra Buana)
}

\section{UTILIZATION OF EIGHT O'CLOCK FLOWER (Turnera subulata) AS A HOST PLANT FOR PREDATORS AND CATERPILLAR PARASITOIDS (Case of PT. Tritunggal Sentra Buana)}

\author{
Ismail $^{1 *}$, Rusli Anwar ${ }^{1}$, Wartomo ${ }^{1}$ \\ ${ }^{1}$ Politeknik Pertanian Negeri Samarinda, Jl. Samratulangi PO BOX 192 Samarinda, \\ Indonesia \\ *corresponding ismailmail2117@gmail.com
}

\begin{abstract}
This research is motivated by the importance of knowledge about alternative pest control that is safe but still supports the achievement of maximum oil palm production so that the balance of the oil palm plantation ecosystem can occur. The purpose of this study is to determine the technical cultivation and benefits of the Turnera subulata flower as a host plant for predators and parasitoids that function as biological agents for caterpillars and can be a reference for controlling caterpillar pests that are safe and still support the achievement of maximum oil palm production. The method used in this research is field observation and documentation from the company. The scope of this research covers the technical aspects of the biological control of caterpillars. This research data uses primary data and secondary data obtained from field observations and literature studies in the form of company reports in the form of percentages. The realization of Turnera subulata planting reached 21,659 $\mathrm{m}$ on CR road and 19,914 m on MR road. The planned planting of Turnera subulata is $57,200 \mathrm{~m}$ on the CR road and $45,823 \mathrm{~m}$ on the MR road. For the realization of the planting of Turnera subulata itself using seeds that are ready for planting. To obtain the seedling, the company conducts its nurseries. The seedling technique was done using the stem cutting technique. The stems for the cutting technique were taken from the Turnera subulata plant stems that have grown large. The type of stem taken is the old Turnera subulata plant stem. For seed care, the seeds are always watered every morning and evening like other flower plants. For the natural enemy insects, been proven that there are 6 natural enemy insects associated with Turnera subulata plants, 3 predators, and 3 parasitoids, each with a large enough number of insects. The types are Eocanthecona furcellata, Cosmolestes sp., Sycannus dichotomus, Spinaria spinator, Fornicia sp., and Chaetexorista javana. The development and the implementation of a control system are by optimizing the conservation and utilization of these biological control agents is a wise step to obtain an effective, efficient and environmentally friendly technique for controlling caterpillars. The presence of Turnera subulata plants can be used to suppress the development of pests in oil palm plantations by increasing the potential for natural enemies, both predators, and parasitoids. The diversity of wild plants with flowers can increase the variety of insects so that the balance of the ecosystem occurs.
\end{abstract}

Keywords: Natural Enemy Insects, Fire Caterpillars, and Turnera subulata

\section{PENDAHULUAN}

Kelapa sawit adalah tumbuhan industri yang berguna sebagai penghasil minyak masak, minyak industri maupun minyak bahan bakar. Pohon Kelapa Sawit terdiri dari dua spesies yaitu elaeis guineensis dan elaeis oleifera yang digunakan untuk pertanian komersil dalam pengeluaran minyak kelapa sawit. Pohon Kelapa Sawit elaeis guineensis, berasal dari Afrika barat diantara Angola dan 
Ismail, Anwar, R., dan Wartomo .(2021) "Pemanfaatan Bunga Pukul Delapan (Turnera subulata) Sebagai Tanaman Inang Bagi Predator Dan Parasitoid Ulat Api (Studi Kasus PT. Tritunggal Sentra Buana)", Jurnal Agriment, 6(2).

Gambia, pohon kelapa sawit elaeis oleifera, berasal dari Amerika tengah dan Amerika selatan. Kelapa sawit menjadi populer setelah revolusi industri pada akhir abad ke-19 yang menyebabkan tingginya permintaan minyak nabati untuk bahan pangan dan industri sabun (Anonim, 2007).

Hama dan penyakit adalah salah satu faktor yang harus diperhatikan dalam budidaya tanaman kelapa sawit. Hama merupakan hewan yang menganggu dan menyebabkan kerugian bagi perkebunan kelapa sawit. Baik kerugian langsung maupun tidak langsung. Keberadaan hama di perkebunan kelapa sawit perlu dkendalikan dengan benar agar produktivitas tidak menurun. Dikatakan sebagai hama pasti dapat menyebabkan kerugian, namun pada teorinya untuk pengendalian hama itu sendiri harus dilihat dalam ambang ekonomi tanaman itu sendiri (Maruli, 2011). Sedangkan, penyakit tanaman adalah penyimpangan dari keadaan normal. Suatu tanaman dapat dikatakan sehat atau normal jika tanaman tersebut dapat menjalankan fungsi-fungsi fisiologis dengan baik, seperti pembelahan dan perkembangan sel, pengisapan air dan zat unsur hara, fotosintesis dan lain-lain. Gangguan pada proses fisiologis atau fungsi-fungsi tanaman dapat menimbulkan penyakit (Maruli, 2011).

$$
\text { Hama utama yang sering }
$$
menyerang tanaman kelapa sawit menghasilkan di PT. Tritunggal Sentra Buana adalah ulat pemakan daun kelapa sawit (UPDKS) seperti ulat api dan ulat kantong yang secara signifikan akan menurunkan produktivitas tanaman. Diperkirakan penurunan produksi mencapai $40-78 \%$ pada 2 tahun setelah terjadi kehilangan daun sebesar $50 \%$. Ulat api yang sering dijumpai adalah Setothosea asigna, Setora nitens, Darna trima, dan Darna diducta. Sedangkan ulat kantong yang sering dijumpai adalah Mahasena corbetti, dan Metisa plana.

Pengendalian hama menggunakan pestisida sintetik hingga saat ini masih merupakan teknik pengendalian yang utama. Akan tetapi penggunaan insektisida sintetik yang tidak bijaksana telah menjadi ancaman bagi kelestarian makhluk hidup. Oleh sebab itu, perlu dicari alternatif pengendalian hama yang bersifat aman namun tetap mendukung dalam pencapaian produksi tanaman yang maksimal. Salah satu komponen pengendalian dalam konsep pengendalian hama terpadu (PHT) yang dapat memperkuat ekosistem adalah dengan pengendalian biologi menggunakan agensi hayati seperti parasitoid dan predator. Nasution (2016) mengatakan bahwa parasitoid membunuh inangnya secara perlahan-lahan dengan cara menumpang hidup sementara waktu pada tubuh inangnya. Predator sifatnya memangsa serangga hama lain untuk makanannya.

Untuk memperbanyak parasitoid dan predator di perkebunan kelapa sawit dapat dilakukan dengan berbagai cara seperti mengurangi penggunaan insektisida yang dapat membunuh musuh alami serta menyediakan makan bagi imago parasitoid tersebut. Imago parasitoid tersebut memperoleh makanan dari madu (nektar yang dihasilkan oleh berbagai macam tumbuhan). Makanan (nektar) bagi parasitoid atau musuh alami lainnya banyak tersedia pada tanaman berbunga seperti Turnera subulata, Antigonon leptopus, Turnera ulmifolia, Euphorbia heterophylla, Cassia tora, Borreria alata, dan Elephantopus tomentosus (Susanto dkk, 2010). Di PT. Tritunggal Sentra Buana, pemanfaatan tanaman berbunga telah berada dalam tahap perawatan. Sejauh ini telah tercatat ada 2 jenis tanaman berbunga yang telah 
diaplikasikan di lapangan yaitu Turnera subulata dan Antigonon leptopus.

Adapun tujuan dilakukan penelitian ini untuk mengetahui budidaya serta manfaat bunga Turnera subulata, mengetahui jumlah rata-rata serangga yang berasosiasi pada tanaman Turnera subulata dan mengetahui tingkat pengaruh serangga terhadap perkembangan populasi ulat api. Hasil yang diharapkan adalah penelitian ini dapat dimanfaatkan dalam rangka pengendalian laju populasi hama ulat api dengan pengendalian biologi serta mampu mengurangi pemakaian pestisida kimiawi.

\section{METODOLOGI}

Penelitian ini dilakukan di PT. Tritunggal Sentra Buana, Kecamatan Muara Badak, Kabupaten Kutai Kartanegara, Provinsi Kalimantan Timur. Waktu penelitian dimulai dari bulan September sampai dengan bulan November.

Dalam hal pengumpulan data ini, penulis terjun langsung pada objek penelitian untuk mendapatkan data yang valid, maka peneliti menggunakan metode sebagai berikut:

\section{Metode Observasi}

Menurut Arikunto (2006) observasi adalah mengumpulkan data atau keterangan secara langsung ke tempat yang akan diselidiki. Sedangkan menurut Suardeyasasri (2010) kata observasi berarti suatu pengamatan yang teliti dan sistematis, dilakukan secara berulangulang. Metode observasi adalah suatu metode pengumpulan data yang dilakukan dengan cara mengadakan pengamatan dan pencatatan secara sistematis baik secara langsung maupun secara tidak langsung pada tempat yang diamati.

Observasi langsung ini dilakukan peneliti untuk mengoptimalkan data mengenai budidaya tanaman Turnera subulata dalam pengendalian hayati ulat api pada perkebunan kelapa sawit serta populasi serangga musuh alami (predator dan parasitoid) pada tanaman Turnera subulata.

\section{Metode Dokumentasi}

Melalui metode dokumentasi, peneliti gunakan untuk menggali data pengendalian hama ulat api serta foto-foto dokumenter pada saat proses pengendalian hama ulat api untuk disesuaikan dengan hasil pengamatan di lapangan.

Prosedur peneitian ini terdiri dari tahap ke-1 melaksanakan dan mengamati teknis budidaya tanaman Turnera subulata (pembibitan dan penanaman di blok).

Tahap ke-2 melakukan sensus pengamatan serangga musuh alami pada tanaman Turnera subulata yang ada pada blok sample untuk mengetahui jenis dan populasi serangga musuh alami yang berasosiasi pada tanaman tersebut. Sensus dilakukan dengan cara mengamati 10 sample pada masing-masing blok. Luas setiap sample pengamatan serangga pada tanaman Turnera subulata yaitu $1 \times 7$ $\mathrm{m}$ atau sama dengan $7 \mathrm{~m}^{2}$.

Tahap ke-3 melakukan sensus pengamatan serangga musuh alami pada beberapa jenis gulma lunak seperti Ageratum conyzoides dan Nephrolephis biserrata yang ada pada blok sample yang tidak ditanami Turnera subulata untuk mengidentifikasi inang lain dari serangga musuh alami.

Tahap ke-4 meminta data hasil studi perusahaan terkait serangan ulat api 1 tahun terakhir pada blok sample.

Tahap ke-5 menganalisa data tingkat serangan ulat api pada blok sample yang ditanami Turnera subulata dan blok sampe yang tidak ditanami Turnera subulata (control).

Analisis data yang digunakan pada penelitian ini adalah dengan cara menghitung persentase sengan ulat api pada blok control dan blok yang ditanami 
Ismail, Anwar, R., dan Wartomo .(2021) "Pemanfaatan Bunga Pukul Delapan (Turnera subulata) Sebagai Tanaman Inang Bagi Predator Dan Parasitoid Ulat Api (Studi Kasus PT. Tritunggal Sentra Buana)", Jurnal Agriment, 6(2).

Turnera subulata. Setelah itu, penulis melakukan perbandingan persentase serangan antara blok control dan blok yang ditanami Turnera subulata dengan menggunakan tabel dan diagram.

\section{HASIL DAN PEMBAHASAN}

\section{Pengembangan Tanaman Turnera subulata}

Realisasi penanaman Turnera subulata mencapai angka $21.659 \mathrm{~m}$ di jalan CR dan 19.914 m di jalan MR. Untuk rencana penanaman Turnera subulata sebanyak $57.200 \mathrm{~m}$ di jalan CR dan $45.823 \mathrm{~m}$ di jalan MR. untuk realisasi penanaman Turnera subulata sendiri menggunakan bibit yang telah siap tanam.

Untuk memperoleh bibit, perusahaan melakukan pembibitan sendiri. Teknik pembibitan dilakukan menggunakan teknik stek batang. Batang yang akan distek diambil dari batang tanaman Turnera subulata yang sudah tumbuh besar. Untuk jenis batang yang diambil adalah batang tanaman Turnera subulata yang sudah tua. Untuk perawatan bibit, bibit selalu disiram setiap pagi dan sore layaknya tanaman bunga lainnya.

Setelah diaplikasikan di lapangan, tanaman Turnera subulata tetap perlu dirawat dan diberi pupuk. Untuk perawatan, tanaman Turnera subulata harus selalu dibersihkan dari gulma lunak yang sering tumbuh disekelilingnya. Ketika sudah tumbuh besar, tanaman Turnera subulata harus selalu dipangkas agar terlihat rapih dan tidak mengganggu akses untuk masuk ke dalam blok. Sedangkan untuk pupuk, perusahaan menggunakan jangkos yang diletakkan disekeliling tanaman Turnera subulata sebagai pengganti pupuk kimia dan agar lebih hemat biaya.

\section{Keberadaan Serangga Predator dan Parasitoid}

Berikut ini adalah tabel data rekapitulasi hasil sensus serangga musuh alami di PT. Tritunggal Sentra Buana:

Tabel 1. Data Hasil Pengamatan Serangga Musuh Alami

\begin{tabular}{ccccc}
\hline \multirow{2}{*}{ No } & \multirow{2}{*}{ Nama Serangga } & \multicolumn{2}{c}{ Jumlah Serangga $/ \mathrm{m}^{2}($ Ekor) } & \multirow{2}{*}{ Keterangan } \\
\cline { 3 - 4 } & & Turnera subulata & Tanaman Lain & \\
\hline 1. & Eucanthecona furcellata & 1 & 0 & Predator \\
2. & Cosmoletestes & 1 & 0 & \\
3. & Sycannus dichotomus & 1 & 0 & \\
4. & Spinaria spinator & 2 & 0 & Parasitoid Larva \\
5. & Fornicia sp. & 2 & 0 & Parasitoid Telur \\
6. & Chaetexorista javana & 1 & 0 & Parasitoid \\
& & & & Kepompong \\
\hline
\end{tabular}

Pada tabel 1 menunjukan ada 6 serangga musuh alami yang berasosiasi pada tanaman Turnera subulata, 3 predator dan 3 Parasitoid dengan masingmasing jumlah serangga yang bisa terbilang banyak. Adapun jenisnya yaitu Eocanthecona furcellata, Cosmolestes sp., Sycannus dichotomus, Spinaria spinator, Fornicia sp., dan Chaetexorista javana. Selain itu, terdapat beberapa serangga lain yang berasosiasi pada tanaman Turnera subulata seperti lebah, lalat dan semut. Sedangkan pada tanaman lain sama sekali tidak didapati serangga musuh alami baik itu predator maupun parasitoid. Hal ini menunjukkan bahwa tanaman Turnera subulata memiliki sesuatu yang dibutuhkan oleh serangga musuh alami untuk bertahan hidup. Maka dari itu kelestarian tanaman Turnera 
subulata perlu diperhatikan untuk meningkatkan populasi serangga musuh alami.

\section{Serangan Hama Ulat Api}

Berikut adalah data rekapitulasi serangan ulat api di PT. Tritunggal Sentra Buana sepanjang tahun 2020 pada tabel 2.

Dari tabel 2 menunjukan bahwa serangan ulat api setiap periode sensus mengalami kenaikan. Akan tetapi, untuk blok yang ditanami Turnera subulatai naik tidak signifikan. Sedangkan, pada blok yang tidak ditanami Turnera subulata (control) mengalami kenaikan yang cukup signifikan. Hal ini menyimpulkan bahwa tanaman Turnera subulata mempunyai pengaruh besar terhadap pengendalian serangan ulat api pada perkebunan kelapa sawit.
Pada bulan Januari menunjukan angka serangan 0 ekor/pelepah pada blok yang ditanami Turnera subulata, sedangkan pada blok control mencapai angka 0,3 ekor/pelepah. Pada bulan April masih menunjukan angka serangan 0 ekor/pelepah pada blok yang ditanami Turnera subulata, sedangkan pada blok control naik menjadi 0,4 ekor/pelepah. Begitupun pada bulan Juli, angka serangan masih sama dengan bulan Januari dan April pada blok yang ditanami Turnera subulata, sedangkan pada blok control mulai naik cukup tinggi ke angka 1 ekor/pelepah. Dan pada akhir periode sensus, angka serangan pada blok yang ditanami Turnera subulata mulai naik ke angka 0,1 ekor/pelepah dan pada blok control naik sangat tinggi ke angka 2,7 ekor/pelepah.

Tabel 2. Serangan Ulat Api

\begin{tabular}{|c|c|c|c|c|c|c|c|c|c|c|c|c|c|c|}
\hline \multirow{3}{*}{ No } & \multirow{3}{*}{ Blok } & \multirow{3}{*}{ Sampel } & \multicolumn{12}{|c|}{ Bulan } \\
\hline & & & \multicolumn{3}{|c|}{ Januari } & \multicolumn{3}{|c|}{ April } & \multicolumn{3}{|c|}{ Juli } & \multicolumn{3}{|c|}{ Oktober } \\
\hline & & & $\begin{array}{l}\text { Jml. } \\
\text { Ulat }\end{array}$ & $\begin{array}{l}\text { Ekor/ } \\
\text { plph }\end{array}$ & $\begin{array}{c}\text { Rata- } \\
\text { rata }\end{array}$ & $\begin{array}{l}\text { Jml. } \\
\text { Ulat }\end{array}$ & $\begin{array}{l}\text { Ekor } \\
\text { /plph }\end{array}$ & $\begin{array}{c}\text { Rata- } \\
\text { rata }\end{array}$ & $\begin{array}{l}\text { Jml. } \\
\text { Ulat }\end{array}$ & $\begin{array}{l}\text { Ekor } \\
\text { /plph }\end{array}$ & $\begin{array}{c}\text { Rata- } \\
\text { rata }\end{array}$ & $\begin{array}{l}\text { Jml. } \\
\text { Ulat }\end{array}$ & $\begin{array}{l}\text { Ekor } \\
\text { /plph }\end{array}$ & $\begin{array}{c}\text { Rata- } \\
\text { rata }\end{array}$ \\
\hline 1. & A25 & turnera & - & - & & - & - & & 1 & - & & 3 & 0,1 & \\
\hline 2. & B39 & turnera & 1 & - & 0 & 3 & - & 0 & 6 & 0,1 & 0 & 8 & 0,1 & 0,1 \\
\hline 3. & B16 & turnera & - & - & & 1 & - & & 3 & 0,1 & & 4 & 0,1 & \\
\hline 4. & A37 & Control & 11 & 0,2 & & 16 & 0,2 & & 49 & 0,8 & & 124 & 1,9 & \\
\hline 5. & B35 & Control & 23 & 0,5 & 0,3 & 29 & 0,6 & 0,4 & 78 & 1,6 & 1 & 193 & 3,9 & 2,7 \\
\hline 6. & A26 & Control & 16 & 0,2 & & 22 & 0,3 & & 56 & 0,9 & & 167 & 2,6 & \\
\hline
\end{tabular}

\section{Perbandingan Serangan Ulat Api}

Intensitas serangan ulat api pada masing-masing blok sample ditunjukan pada tabel 1-5. Intensitas serangan ulat api di tahun 2020 pada blok yang tidak ditanami Turnera subulata menunjukan angka serangan rata-rata sebanyak 0.3 ekor/pelepah pada bulan Januari, 0.4 ekor/pelepah pada bulan April, 1 ekor/pelepah pada bulan juli, hingga 2,7 ekor/pelepah pada bulan Oktober. Angka tersebut jauh lebih tinggi jika dibandingkan dengan blok yang ditanami Turnera subulata yang hanya terkena serangan pada akhir periode sensus yaitu pada bulan Oktober (0,1 ekor/pelepah).

Intensitas serangan yang tinggi pada blok yang tidak ditanami Turnera subulata disebabkan oleh tidak adanya serangga musuh alami baik itu predator maupun parasitoid yang dapat menekan populasi ulat api pada tanaman kelapa sawit. Hal ini dikarenakan tidak adanya tanaman inang bagi serangga musuh alami pada blok yang tidak ditanami Turnera subulata. Perkembangan musuhmusuh alami suatu hama akan terhambat apabila tidak tersedia makanan dan tempat untuk berkembang biak (Dhesmier de Chenon et. al, 2002).

\section{Jenis Serangga yang Berasosiasi pada Tanaman Turnera subulata}

Terdapat beberapa jenis serangga yang berasosiasi pada tanaman Turnera subulata, namun ada dua serangga yang 
Ismail, Anwar, R., dan Wartomo .(2021) "Pemanfaatan Bunga Pukul Delapan (Turnera subulata) Sebagai Tanaman Inang Bagi Predator Dan Parasitoid Ulat Api (Studi Kasus PT. Tritunggal Sentra Buana)", Jurnal Agriment, 6(2).

mampu menekan laju populasi hama ulat api yaitu serangga predator dan parasitoid.

\section{a. Serangga Predator}

Predator merupakan salah satu musuh alami yang efektif dalam pengendalian hama ulat api pada perkebunan kelapa sawit. Predator memangsa organisme lain yang hidup di alam untuk memenuhi kebutuhan hidupnya. Keberadaan predator di alam sangat efektif dalam menekan perkembangan serangga hama, sebab satu ekor predator dapat memakan mangsanya dalam waktu singkat dan dalam jumlah banyak (Satriawan, 2011). Beberapa spesies predator yang berasosiasi dengan tanaman Turnera subulata pada blok sample diantaranya Eocanthecona furcellata, Cosmolestes $s p$ dan Sycanus dichotomus.

\section{b. Serangga Parasitoid}

Parasitoid merupakan salah satu musuh alami yang efektif dalam mengendalikan serangga hama di suatu ekosistem. Keanekaragaman parasitoid bergantung pada keanekaragaman inang yang sebagian besar merupakan serangga fitofag, sedangkan keanekaragaman fitofag bergantung pada ketersediaan tanaman inang di suatu ekosistem (Luqmana et al., 2016). Oleh karena itu keanekaragaman vegetasi disuatu ekosistem akan dapat meningkatkan persentase parasitisasi serangga fitofag oleh parasitoid.

$$
\text { Menurut Sembel }
$$

Mekanisme kerja parasitoid betina dapat meletakkan telur di permukaan inang kemudian setelah menetas akan menghisap cairan inang atau dengan dengan memasukan telur melalui ovipositornya ke dalam serangga inang selanjutnya telur parasit akan berkembang di dalam tubuh inang.
Beberapa spesies parasitoid yang berasosiasi dengan tanaman Turnera subulata pada blok sample diantaranya Spinaria spinator, Fornicia sp, dan Chaetexorista javana. Masing-masing serangga parasitoid mempunyai cara kerja berbeda-beda pada saat memarasitisasi tubuh inangnya. Ada yang memarasit larva, telur dan kepompong dari inangnya.

\section{KESIMPULAN}

1. Teknik budidaya tanaman Turnera subulata perlu terus dikembangkan untuk menunjang pertumbuhana tanaman Turnera subulata serta kelestarian hidup musuh alami bagi ulat api.

2. Keberadaan tanaman Turnera subulata dapat menunjang kehidupan serangga predator dan parasitoid. Karena tanaman Turnera subulata merupakan salah satu sumber makanan dan tempat berlindung bagi serangga predator dan parasitoid. Serangga predator dan parasitoid tersebut berperan penting sebagai faktor pengendali populasi hama ulat api secara alami di perkebunan kelapa sawit, sehingga perlu dijaga kelestariannya.

3. Dalam kurun waktu 1 tahun terakhir terbukti didapati angka serangan hama ulat api yang lebih rendah pada blok sampel yang ditanami Turnera subulata dibandingkan dengan blok yang tidak ditanami Turnera subulata. Tanaman Turnera subulata menjadi habitat serangga musuh alami yang aktif mengendalikan laju populasi hama ulat api. Dari hasil penelitian terbukti didapati berbagai macam serangga musuh alami yang berasosiasi pada tanaman Turnera 
subulata baik predator (Eucanthecona furcellata, Cosmolestes sp. dan Sycannus dichotomus) maupun parasitoid (Spinaria spinator, Fornicia sp. dan Chaetexorista javana) yang dikenal aktif mengendalikan laju populasi ulat api pada perkebunan kelapa sawit.

\section{DAFTAR PUSTAKA}

Anonim. 2007. Definisi Tanaman Sawit. Jakarta: Dinas Perkebunan Indonesia.

Arikunto S. 2002. Prosedur Penelitian Suatu Pendekatan Praktek. Jakarta: PT. Rineka Cipta.

Chenon R. D., Hasibuan H. S., Sudharto P. S., Purba R. Y. 2002. Importance of Food Plants for Parasitoids in The Control of Nettle Cateroillars and Bagworms in Oil Palm Plantations. Paper Presented in International Oil Palm Conference. Nusa Dua Bali.

Maruli dan Pardamean. 2011. Cara Cerdas Mengelola Perkebunan Kelapa Sawit. Yogyakarta: Lily Publisher.

Nasution N. 2016. Keanekaragaman Laba-Laba (Araneae) Pada Ekosistem Sawah dengan Beberapa Pola Tanam di Kota Padang. Jurnal Biologi dan Pendidikan Biologi. Vol.2 No.1: 13-18.

Satriawan R. 2011. Kelimpahan Populasi Ulat Api (Lepidoptera: Limacodidae) dan Ulat Kantung (Lepidoptera: Psychidae) serta Predator pada Perkebunan Kelapa Sawit (Elaeisguineensis Jacq.) Cikidang Plantation Estate, Sukabumi. Skripsi. Bogor: Institut Pertanian Bogor.

Sembel D. T. 2010. Pengendalian Hayati Hama-hama Serangga Tropis dan Gulma. Yogyakarta: Andi Offset

Suardeyasasri. 2010. Metode Penelitian Kualitatif.

http://www.google.com/url?sa $=j \& q=p$ enelitian+metode+observasi+di+seko lah\&source=web\&cd=3\&cad=rja\&ved

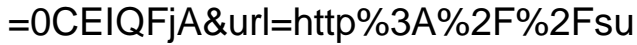
ardeyasasri.files.wordpress.com\%2F
2010\%2F02\%2Fmetode-penelitiankualitatif.pdf\&ei $=50$ jvUPb4HYfl1QXB 44Bg\&usg=AFQjCNHpw2gbe8KKlsF a1QV1TxPqG1SjrA\&bvm=bv. 135770 0187,d.bmk. (5 Juni 2020).

Susanto A. dan Prasetyo E. A. 2017. Identifikasi Hama dan Penyakit Kelapa Sawit Beserta Pengendaliannya. Medan: Pusat Penelitian Kelapa Sawit.

Nama Belakang, A. (Nama Depan Inisial Huruf), \& Nama Belakang, B. B. (Tahun). Judul Naskah. Penerbit, Volume jika ada (Nomer/Edisi), Halaman atau URL 